\title{
Choosing Social Situations: Two Investigations of Self-Monitoring Processes
}

\author{
Mark Snyder and Steve Gangestad \\ University of Minnesota
}

\begin{abstract}
Two investigations examined the processes by which individuals choose social situations. In the first investigation, participants chose to enter or not to enter a situation that called for behavioral expressions of extraversion. For high selfmonitoring individuals, willingness to enter this situation was a direct reflection of the clarity with which the extraverted character of the situation was defined. For low self-monitoring individuals, willingness to enter this situation was a direct reflection of their personal dispositions within the domain of extraversion and introversion. In the second investigation, participants were assigned to a situation and were allowed to indicate how the situation might be changed to make them more willing to enter it. The transformed situations of high self-monitoring individuals were of relatively clearly defined character. The transformed situations of low self-monitoring individuals were relatively congruent with their own extraverted or introverted dispositions. The processes by which high self-monitoring individuals and low self-monitoring individuals facilitate the enactment of their characteristic behavioral orientations are discussed.
\end{abstract}

Theory and research on self-monitoring are concerned with the processes by which individuals plan and enact their behavioral choices in social contexts (for a review, see Snyder, 1979). According to the self-monitoring theoretical formulation, two primary sources of information are available to individuals to guide these activities: information about situational and interpersonal specifications of appropriate behavior, and information about their own inner states, attitudes, and dispositions. Furthermore, according to the self-monitoring formulation, individuals differ meaningfully in the extent to which they rely on either source of information to guide their actions in social settings.

In regulating their social behavior, those

This research and the preparation of this manuscript were supported in part by National Seience Foundation Grants BNS 77-11346 and BNS 82-07632 to Mark Snyder. Portions of this manuscript were written while Mark Snyder was a Fellow of the Center for Advanced Study in the Behavioral Sciences, Stanford, California. For their comments on the manuscript, we thank Nancy Cantor, William Ickes, Edward E. Jones, and Dale T. Miller.

Requests for reprints should be sent to Mark Synder, Laboratory for Research in Social Relations, Department of Psychology, University of Minnesota, 75 East River Road, Minneapolis, Minnesota 55455. individuals who are relatively situationally guided (high self-monitoring individuals, identified by their relatively high scores on the Self-Monitoring Scale; Snyder, 1974) are markedly sensitive and responsive to social and interpersonal cues to situational appropriateness. Their social behavior displays pronounced situation-to-situation specificity (e.g., Lippa, 1976; Snyder \& Monson, 1975). At the same time, correspondence between behavior and attitude often is minimal for these high self-monitoring individuals (e.g., Snyder \& Swann, 1976; Snyder \& Tanke, 1976). By contrast, in regulating their social behavior, those individuals who are relatively dispositionally guided (low self-monitoring individuals, identified by their relatively low scores on the Self-Monitoring Scale; Snyder, 1974) are less responsive to situational and interpersonal specifications of appropriate behavior (e.g., Lippa, 1976; Snyder \& Monson, 1975). Rather, these individuals guide their behavioral choices on the basis of information from relevant inner sources, as reflected in the characteristically substantial correspondence between their behavior in social contexts and their relevant underlying attitudes and dispositions (e.g., Snyder \& Swann, 1976; Snyder \& Tanke, 1976; Zanna, Olson, \& Fazio, 1980). 
These characteristic behavioral orientations of high self-monitoring individuals and low self-monitoring individuals appear to be clearly defined. It is as if high self-monitoring individuals chronically strive to appear to be the type of person called for by each situation in which they find themselves, and it is as if low self-monitoring individuals strive to display their own personal dispositions and attitudes in each situation in which they find themselves. Our concern here is with strategic activities by which high selfmonitoring individuals and low self-monitoring individuals may facilitate and promote the enactment of their characteristic behavioral orientations. That is, what strategies can high self-monitoring individuals use to make it easy for themselves to be the appropriate person for each different situation? What strategies can low self-monitoring individuals use to make it easy for themselves to act in accord with their private dispositions? We suggest that one set of strategies involves the situations, surroundings, and circumstances within which individuals choose to live their lives.

In the course of their lives, individuals typically have considerable freedom to choose where to be, when to be there, and with whom to be there. Accordingly, the social settings and interpersonal contexts in which individuals find themselves are partially of their own choosing. What considerations might guide these choices of situations? It has been suggested that these choices of the settings in.which to live one's life may reflect features of one's personal attributes, including one's characteristic dispositions, one's attitudes, and one's conceptions of self (Snyder, 1981). Thus, for example, the choice to spend time in situations that promote gregarious behaviors (e.g., parties) may reflect one's gregarious nature; in contrast, the choice to spend time in situations that promote intellectual behaviors (e.g., seminars) may reflect one's intellectual inclinations. More generally, individuals may choose to enter and to spend time in situations that provide opportunities for and that facilitate the behavioral expression of their characteristic dispositions (e.g., competitive individuals may seek out situations in which they can compete with other people), their attitudes (e.g., individuals with conservative po- litical attitudes may seek out situations in which they can further the aims of conservative causes), and their conceptions of self (e.g., individuals who believe they are leaders may seek out situations in which they can assume positions of leadership). For an overview of empirical demonstrations of individuals choosing social situations, see Snyder and Ickes (in press).

From the perspective of self-monitoring, it may be that individuals choose to be in situations that are particularly conducive to the enactment of the characteristic behavioral orientations associated with their selfmonitoring propensities. If so, we may pose two questions about the links between these choices and the characteristic behavioral orientations of high self-monitoring individuals and low self-monitoring individuals. First, from a theoretical perspective, are there social situations and interpersonal contexts that are particularly conducive to the enactment of the characteristic behavioral orientation of high self-monitoring individuals and other social situations and interpersonal contexts that are particularly conducive to the enactment of the characteristic behavioral orientation of low self-monitoring individuals? Second (if such social settings do exist), from an empirical perspective, will high self-monitoring individuals and low self-monitoring individuals actually gravitate toward those social contexts that facilitate the enactment of their characteristic behavioral orientations? Let us examine these issues.

What are the features of social situations and interpersonal contexts that would be particularly conducive to the enactment of the behavioral orientation characteristic of high self-monitoring individuals? We suggest that the enactment of this behavioral orientation will be facilitated in interpersonal settings that provide clearly defined situational guidelines for high self-monitoring individuals to use in molding and tailoring their self-presentation and social behavior to their situations. Therefore, we would expect that high self-monitoring individuals would choose, whenever possible, to enter and to spend time in social situations and interpersonal settings where there are clearly defined images of the type of person who would be ideally suited for that situa- 
tion. More specifically, a clearly defined image of the prototypic individual called for by the situation provides operating guidelines for enacting a pattern of self-presentation by meeting two criteria.

First, a situation of clearly defined character provides precise and unambiguous specifications of the person called for by the situation. That is, a clearly defined character provides specifications at the relatively precise level of instrumental and expressive behaviors that constitute a situationally appropriate pattern of self-presentation. For example, a situation of clearly defined character does not simply specify that the display of sociability is appropriate to that situation, but also specifies the manner and form that this display of sociability should take.

Second, a situation of clearly defined character provides specifications of the type of person called for by the situation in a coherent, consistent fashion so that behavioral specifications do not conflict with one another. For example, a situation of clearly defined character does not specify that an individual display both assertiveness and reticence. Images of the type of person who would be well-suited for the situation that meet both of these criteria allow high selfmonitoring individuals to become the persons called for by their situations.

What are the features of social situations and interpersonal contexts that would be particularly conducive to the enactment of the behavioral orientation of low self-monitoring individuals? We suggest that the enactment of this behavioral orientation will be facilitated in interpersonal settings that permit low self-monitoring individuals to be themselves. Therefore, we might expect that low self-monitoring individuals would choose, whenever possible, to enter and to spend time in social situations' and interpersonal settings where it is appropriate to express and reflect their own attitudes, traits, or dispositions. In such contexts, it will be possible for low selfmonitoring individuals to engage in behaviors that are not only congruent with their own personal attributes but also appropriate to their situations.

Do high self-monitoring individuals systematically choose to enter and to spend time in interpersonal settings that provide clear specifications of the type of character one ought to be in those situations? Do low selfmonitoring individuals systematically choose to enter and to spend time in interpersonal settings that call for the display of their own personal attributes? To answer these questions, we conducted the first investigation.

\section{Investigation 1}

In this investigation, we allowed individuals to choose to enter or not to enter a social situation that called for the expression of sociability. For some individuals, the sociable character called for by the situation was defined in minimal terms-sufficient to define the situation as one that called for the display of sociability but not sufficient to specify the precise form that the display of sociability should take. For other individuals, the sociable character called for by the situation was defined in clear, precise, and unambiguous fashion to provide a detailed set of specifications of the precise instrumental and expressive behaviors by which sociability was to be displayed. We expected that high self-monitoring individuals would be highly responsive to this difference between the two situations. That is, we expected high self-monitoring individuals to be relatively unwilling to enter the situation of minimally defined sociable character, but relatively willing to enter the situation of clearly defined sociable character. At the same time, we expected that low self-monitoring individuals would be relatively unaffected by the clarity of the character of the situation. However, we did expect that the willingness of low self-monitoring individuals to enter either situation would be a direct reflection of their own personalities. That is, we expected that extraverted low-self-monitoring individuals would be relatively willing to enter either sociable situation and that introverted low-self-monitoring individuals would be relatively unwilling to enter either sociable situation.

\section{Method}

\section{Participants}

The participants were 125 male and female undergraduates enrolled in introductory psychology at the University of Minnesota who participated in this investigation for course credit. Scores on the Self-Monitoring Scale (Snyder, 1974) and the Extraversion scale of the 
Eysenck Personality Inventory (Eysenck \& Eysenck, 1968), which were administered as part of a considerably larger questionnaire survey, were available for all participants.

\section{Procedure}

Participants, who had been scheduled in small group sessions, received booklets that provided them an opportunity to choose to enter and to spend time in or not to enter and not to spend time in a social situation that called for the expression of social extraversion. Specifically, participants learned that the experimenters were convening discussion groups, each of which would be composed of four students who would discuss a court case and reach a verdict. Participants also learned that in each four-person discussion group there would be a confederate of the experimenters who, for the 20-30minute duration of the discussion, would behave in a socially extraverted manner.

For the participants assigned randomly to the minimally-defined-character condition, the socially extraverted character required of confederates in the groupdiscussion social situations was defined in minimal terms. These participants learned only the global traits typically associated with extraversion (i.e., "We will need a confederate who will be outgoing, talkative, outspoken, self-assured, and confident-in general, extraverted--during the discussion.") but learned nothing of the specific expressive behaviors by which confederates were to manifest extraversion in this social situation.

For the participants assigned randomly to the clearlydefined-character condition, the socially extraverted character required of confederates in the group-discussion social situations was defined in substantially more precise and detailed fashion. In addition to learning the global traits typically associated with social extraversion, these participants received these specifications of the manner in which confederates were to manifest social extraversion in this particular social situation:

We. want the confederate to agree with whatever a particular person in the discussion says-specifically, the person seated on his or her right. That is, the confederate should endorse the position of that person and disagree with opposing viewpoints, should they arise. The confederate can express and communicate his or her position by using gestures and other nonverbal expressions-nodding when the person on his or her right makes a point and shaking his or her head or communicating disagreement through facial expressions when someone else makes an opposing statement. The confederate should make these expressions confidently and when possible should verbally back up the position.

All participants then reported their willingness to enter and to spend time in this social situation. Specifically, they answered (on 7-point scales on which $1=$ not at all and $7=$ very) these six questions: (a) How willing would you be to participate as the confederate described? (b) How comfortable would you feel being the confederate? (c) How natural would you act in being the confederate? (d) How much could you be yourself as the confederate? (e) How good a job do you think you could do as the confederate? and (f) How much would you enjoy the discussion as the confederate?

\section{Results}

We have predicted that high self-monitoring individuals, but not low self-monitoring individuals, would be relatively willing to enter and to spend time in the group-discussion social situation in the clearly-defined-character condition and relatively unwilling to enter and to spend time in the minimally-defined-character condition. We also predicted that for low self-monitoring individuals, but not for high self-monitoring individuals, extraverts would be relatively willing and introverts would be relatively unwilling to enter and to spend time in the group-discussion social situation. To test these predictions, we first constructed a global measure of willingness to enter and to spend time in the group-discussion social situation by calculating for each participant the sum of his or her answers to the six separate questions, each of which had inquired about different manifestations of his or her willingness to enter and to spend time in the group-discussion social situation.'

We then entered participants' scores on this global measure of willingness to enter and to spend time in the group-discussion social situation into a 2 (high self-monitoring individuals vs. low self-monitoring individuals) $\times 2$ (minimally defined character vs. clearly defined character) $\times 2$ (extraverted individuals vs. introverted individuals) unweighted means analysis of variance. ${ }^{2}$ Within

\footnotetext{
${ }^{1}$ Answers to the individual questions and answers to the entire set of questions are highly correlated. Itemtotal correlations (with that particular item removed) range from $r=.70$ to $r=.77$. Participants' scores on the six-item measure of willingness to enter and to spend time in the group-discussion social situation range from 7 to 42 , with a mean of 27.79 and a standard deviation of 8.53. Internal consistency of the six-item measure of willingness to enter and to spend time in the groupdiscussion social situation is .95 , as assessed by Cronbach's coefficient alpha.

${ }^{2}$ Individuals with scores on the Self-Monitoring Scale less than or equal to 12 were classified as low self-monitoring individuals $(n=61)$; those with scores greater than or equal to 13 were classified as high self-monitoring individuals $(n=64)$. Individuals with scores on the Extraversion scale less than or equal to 12 were classified as introverts $(n=58)$; those with scores greater than or equal to 13 were classified as extraverts $(n=67)$.

Although there was a modest correlation $(r=.31)$ between self-monitoring and extraversion for participants in this investigation, the classification procedure
} 
this analysis of variance, we performed a single planned comparison (cf. Hays, 1973) specifically designed to test our theoretical predictions about the interactive influences of self-monitoring propensities, clarity of the character of the situation, and personal dispositions within the domain of extraversion and introversion on willingness to enter and to spend time in the group-discussion social situation. To perform this planned comparison, we assigned weights of +1 to the four conditions where we had predicted that participants would be relatively willing to enter and to spend time in the social situation (i.e., high self-monitoring extraverts and high self-monitoring introverts in the clearly-defined-character condition, and low self-monitoring extraverts in either the minimallydefined-character condition or the clearlydefined-character condition) and weights of -1 to the four conditions where we had predicted that participants would be relatively unwilling to enter and to spend time in the social situation (i.e., high self-monitoring extraverts and high self-monitoring introverts in the minimally-defined-character condition, and low self-monitoring introverts in either the minimally-defined-character condition or the clearly-defined-character condition).

This planned comparison was highly significant, $F(1,117)=11.49, p<.001$. After performing the planned comparison, some

was relatively successful in producing orthogonality between self-monitoring and extraversion. A 2(self-monitoring classification) $\times 2$ (extraversion/introversion classification) analysis of variance with scores on the extraversion measure as the dependent variable revealed some tendency for high self-monitoring individuals to be somewhat more extraverted than low self-monitoring individuals, $F(1,121)=2.91, p<.10$. Separate comparisons revealed that although high self-monitoring individuals classified as extraverts were slightly more extraverted than low self-monitoring individuals classified as extraverts ( $M s=15.98$ and 15.11 , respectively), $t(65)=1.71, p<.10$, high self-monitoring individuals classified as introverts were neither more nor less introverted than low self-monitoring individuals classified as introverts $(M \mathrm{~s}=9.67$ and 9.24 , respectively), $t(56)=$ .55 , ns. More importantly for purposes of testing our predictions, however, the high self-monitoring extraverts differed as much from the high self-monitoring introverts as the low self-monitoring extraverts differed from the low self-monitoring introverts (differences of 6.31 and 5.87 points on the measure of extraversion, respectively), interaction $F<1$. systematic variation not accounted for by the planned comparison remained, $F(6,117)=$ $1.97, p=.08$. An examination of this remaining variation revealed a source of systematic variation independent of the theoretical prediction; specifically, a main effect for self-monitoring such that high self-monitoring individuals were more willing to enter and to spend time in the social situation than were low self-monitoring individuals, $F(1$, $117)=6.06, p<.02$. Aside from this single additional source of variation, the residual amount of systematic variation beyond that accounted for by the theoretical predictions was clearly not significant, $F(5,117)=1.15$, $n s^{3,4}$

${ }^{3}$ We also examined the possible contributions of in-
dividual factors that may exist within the overall mea-
sure of self-monitoring. Specifically, we performed this
analysis of variance three more times, each time allow-
ing a median partition of participants' scores on one of
the three factors suggested by Briggs, Cheek, and Buss
(1980; a similar set of factors has been suggested by
Gabrenya \& Arkin, 1980) to stand in for the catego-
rization based on participants' scores on the overall
measure of self-monitoring that we had used in the
original analysis of variance. These stand-in analyses
revealed that the planned comparison (which, when it
had used the overall measure had been highly signif-
cant, $F(1,117)=11.49, p<.001$ ) was now at least
marginally significant for each of the three factors. For Factor 1, which they have labeled Extraversion, $F(1$, $117)=4.90, p<.05$; for Factor 2, which they have labeled Other-Directedness, $F(1,117)=6.70, p<.02$; for Factor 3, which they have labeled Acting, $F(1$, $117)=3.91, p<.06$. The amount of systematic variation in willingness to enter and to spend time in the social situation accounted for by the planned comparison using even the best performing of these factors is little more than half of that accounted for by the planned comparison employing the overall measure of self-monitoring (for Factor 1, 43\%; for Factor 2, 62\%; for Factor $3,36 \%$ ). It appears that, at least in this analysis, each factor can stand in for the entire measure; nevertheless, no individual factor seems to be a wholly adequate substitute for the entire measure of self-monitoring.

4 When considered individually, the six dependent measures that entered into the global measure of willingness to enter and to spend time in the group-discussion social situation all yielded outcomes similar to those of the global measure. In each case, the amount of predicted systematic variation was substantial and statistically significant, $F \mathrm{~s}$ ranging from $F(1,117)=5.66$, $p<.02$, to $F(1,117)=15.83, p<.001$. In cases where, as with the global measure, the residual variation was significant or marginally significant, $F$ s range from $F(6$, $117)=.94$, $n s$, to $F(6,117)=2.68, p<.05$. Elimination of the self-monitoring main effect reduced the residual variation to nonsignificant levels, $F$ s range from $F(5$, $117)=.65, n s$, to $F(5,117)=1.36, n s$. 
The outcomes of this analysis provide definite support for the predictions derived from our theoretical analysis of the determinants of the willingness of high self-monitoring individuals and low self-monitoring individuals to enter and to spend time in social situations. As we had predicted, high self-monitoring individuals were reliably more willing to enter and to spend time in the groupdiscussion social situation in the clearlydefined-character condition than in the minimally-defined-character condition, $F(1$, $117)=4.92, p<.05$. At the same time, low self-monitoring individuals were neither more nor less willing to enter and to spend time in the group-discussion social situation in the clearly-defined-character condition than' in the minimally-defined-character condition, $F(1,117)=.24, n s$ (for means, see Table 1). Furthermore, as we had predicted, low selfmonitoring extraverts were reliably more willing to enter and to spend time in the group-discussion social situation than were low self-monitoring introverts, $F(1,117)=$ $6.61, p<.02$. At the same time, high selfmonitoring extraverts and high self-monitoring introverts did not differ in their willingness to enter and to spend time in the group discussion social situation, $F(1$, $117)=.94, n s$ (for means, see Table 2$)$.

Table 1

Choosing Situations: Willingness to Enter and to Spend Time in Social Situations of Minimally Defined and Clearly Defined Character

\begin{tabular}{lll}
\hline & \multicolumn{2}{c}{ Situation } \\
\cline { 2 - 3 } $\begin{array}{c}\text { Self-monitoring } \\
\text { classification }\end{array}$ & $\begin{array}{c}\text { Minimally } \\
\text { defined }\end{array}$ & $\begin{array}{l}\text { Clearly } \\
\text { defined }\end{array}$ \\
\hline High self-monitoring & 27.40 & 31.99 \\
$M$ & 34 & 30 \\
$n$ & & \\
Low self-monitoring & 26.60 & 25.59 \\
$M$ & 28 & 33 \\
\hline
\end{tabular}

Note. In this table, the data have been collapsed across the extraverted-individuals versus introverted-individuals factor. Thus, each mean represents the average mean of two cells in the full design.
Table 2

Choosing Situations: Willingness of Introverts and Extraverts to Enter and to Spend Time in Social Situations

\begin{tabular}{|c|c|c|}
\hline $\begin{array}{l}\text { Self-monitoring } \\
\text { classification }\end{array}$ & Introverts & Extraverts \\
\hline \multicolumn{3}{|c|}{ High self-monitoring } \\
\hline $\begin{array}{l}M \\
n\end{array}$ & $\begin{array}{l}28.69 \\
24\end{array}$ & $\begin{array}{l}30.70 \\
40\end{array}$ \\
\hline \multicolumn{3}{|l|}{ Low self-monitoring } \\
\hline $\begin{array}{l}M \\
n\end{array}$ & $\begin{array}{l}23.44 \\
34\end{array}$ & $\begin{array}{l}28.76 \\
27\end{array}$ \\
\hline
\end{tabular}

Note. In this table, the data have been collapsed across the minimally-defined-character versus clearly-definedcharacter factor. Thus, each mean represents the average mean of two cells in the full design.

\section{Investigation 2}

In the first investigation, the willingness of high self-monitoring individuals to enter and to spend time in the experimentally created social situation that called for the behavioral expression of sociability was a direct reflection of the clarity and precision with which the sociable character of that situation was defined. In contrast, the willingness of low self-monitoring individuals to enter and to spend time in that social situation was a direct reflection of their own personal dispositions in the domain of extraversion and introversion. Of course, the findings of the first investigation may be limited to the specific procedures that we used to create experimental situations that allowed us to assess the validity of our theoretical prediction. Specifically, in the first investigation, we varied the clarity of the character called for in the experimentally created social situation by varying the precision of the specifications.

How else might we have varied the clarity of the character called for in the social situation? We have suggested that a clearly defined character of the person called for by the situation is provided by specifications that are precise and unambiguous and also coherent and consistent. From an experimental standpoint, there are two different ways to produce variation in clarity of character. Clarity of character can be varied (as in the first investigation) in terms of the pre- 
cision with which the behavioral specifications for the person called for in the situation are defined. Clarity of character can also be varied in terms of the coherence and consistency of the specifications of the person called for in the situation. To seek converging evidence for our theoretical predictions, we conducted a second investigation in which we distinguished clarity of character in terms of the latter criterion-the coherence and consistency of the behavioral specifications provided within the context of the interpersonal setting.

The second investigation differed from the first investigation in one additional important aspect. In the first investigation, we created situations judged from a theoretical standpoint to be relatively conducive or unconducive to the characteristic behavioral orientations of high self-monitoring individuals and low self-monitoring individuals, and we gave individuals the opportunity to tell us how willing they would be to enter and spend time in such situations. In the second investigation, we again presented participants with a social situation, but instead of asking participants to indicate to us how willing they would be to enter and spend time in this situation, we gave them the opportunity to tell us how the situation could be altered to make them more willing to choose to enter and to spend time in that situation.

Based on our theoretical analysis, we predicted that high self-monitoring individuals would indicate that they would be more willing to enter and to spend time in a transformed social situation associated with a more clearly defined character than that of the original situation. We also predicted that low self-monitoring individuals would indicate that they would be more willing to enter and to spend time in a transformed social situation that called for the display of personal attributes more congruent with their own personal dispositions than did the original situation.

\section{Method}

\section{Participants}

The subjects were 234 male and female undergraduates enrolled in introductory psychology at the University of Minnesota who participated in this investi- gation for course credit. Scores on the Self-Monitoring Scale (Snyder, 1974) and the Extraversion scale of the Eysenck Personality Inventory (Eysenck \& Eysenck, 1968), which were administered as part of a considerably larger questionnaire survey, were available for all participants.

\section{Procedure}

Participants, who had been scheduled in small group sessions, received booklets that provided them an opportunity to transform the character of a social situation so that they would be more willing to enter and to spend time in it. Specifically, participants learned that the experimenters, for purposes of their research, were arranging conversational interactions in which two people would be videotaped as they chatted informally about such things as their past experiences, their current activities, their interests and hobbies, their likes and dislikes, or anything that two people would converse about in the course of becoming acquainted with each other. Participants further learned that, also for purposes of their research, the experimenters had a specific idea of how both participants were to appear during their conversational interaction. Specifically, participants learned that they were to show, during the course of these 10minute social interactions, signs of ten global traits and general dispositions.

For participants assigned randomly to the mostlyextraverted-character condition, seven of these traits were characteristic of extraverted individuals (impulsive, talkative, ambitious, lively, cheerful, confident, active) and three of these traits were characteristic of introverted individuals (reserved, reflective, soft-spoken). For participants assigned randomly to the mostly-introverted-character condition, seven of these traits were characteristic of introverted individuals (reserved, retiring, cautious, quiet, soft-spoken, reflective, studious) and three of these traits were characteristic of extraverted individuals (active, confident, lively). In constructing these mostly extraverted and mostly introverted characters, care was taken to use extraverted and introverted traits that, although generally incongruous, were not direct opposites in meaning.

Participants then were given the opportunity to transform the character of these dyadic social interactions by modifying the set of personal attributes to be displayed by participants in the getting-acquainted conversations. Specifically, participants were told:

We wish to know what would make it easier for you
to be the person we've described in this tape. Carefully
examine the list of ten (10) traits of which the people
in these tapes would give evidence. Suppose that in-
stead of having to give evidence of all ten traits, the
people in the tapes only had to give evidence of six
of these traits. What six (6) traits would you keep on
the list in order to make it easier for you to be the
character? From the list of traits below, please in-
dicate those six traits (by circling each) which would
create a character easier for you to portray, a char-
acter you would be more willing to portray, etc.

By their choices of six traits, participants in the mostly-extraverted-character condition could define the 
Table 3

Transforming Situations: Increasing the Congruence Between the Character of the Situation and One's Own Personal Dispositions

\begin{tabular}{|c|c|c|}
\hline \multirow[b]{2}{*}{$\begin{array}{l}\text { Self-monitoring } \\
\text { classification }\end{array}$} & \multicolumn{2}{|c|}{ Situation } \\
\hline & $\begin{array}{c}\text { Mostly } \\
\text { extraverted } \\
\text { character }\end{array}$ & $\begin{array}{c}\text { Mostly } \\
\text { introverted } \\
\text { character }\end{array}$ \\
\hline \multicolumn{3}{|c|}{ High self-monitoring } \\
\hline$r$ & .15 & .13 \\
\hline$n$ & 39 & 34 \\
\hline \multicolumn{3}{|l|}{ Low self-monitoring } \\
\hline$r$ & $.54^{* *}$ & $.49^{* *}$ \\
\hline$n$ & 31 & 37 \\
\hline
\end{tabular}

Note. Correlations are calculated between participants' scores on extraversion and the number of extraverted traits in their lists of six traits.

$* * p<.01$.

character of this social situation as any one of a set of characters that range from one defined by as many as six extraverted traits (and no introverted traits at all) to one defined by as few as three extraverted traits (and three introverted traits). Similarly, by their choices of six traits, participants in the mostly-introverted-character condition could define the character of this social situation as any one of a set of characters that range from one defined by as many as six introverted traits (and no extraverted traits at all) to one defined by as few as three introverted traits (and three extraverted traits).

By examining the composition of the six traits retained by each participant, it was possible to assess the extent to which he or she had transformed his or her social situation into one that called for a character that was more clearly and consistently defined than that of the situation as originally defined, and the extent to which he or she had transformed his or her social situation into one that called for a character whose personal attributes were more congruent with his or her disposition within the domain of extraversion and introversion.

\section{Results}

We have predicted that: (a) low self-monitoring individuals, more so than high selfmonitoring individuals, would define the character of the situation they would be more willing to enter as one relatively congruent with their own extraverted or introverted dispositions; and (b) high self-monitoring individuals, more so than low selfmonitoring individuals, would define the character of the situation they would be more willing to enter in relatively clear and consistent terms. We examined these hypotheses in two correlation matrixes.

Did low self-monitoring individuals, more so than high self-monitoring individuals, define the character of the situation they would be more willing to enter as one closely resembling their own extraverted or introverted dispositions? To answer this question, we calculated Pearson product-moment correlations between participants' scores on the Extraversion scale of the Eysenck Personality Inventory (Eysenck \& Eysenck, 1968) and the number of extraverted traits that each participant retained in his or her list of six traits. These correlations, calculated separately for high self-monitoring individuals and for low self-monitoring individuals who had been assigned to the mostly-extraverted-character and the mostlyintroverted-character experimental conditions, are displayed in Table $3 .^{5}$

An examination of the magnitude of these correlations reveals that for low self-monitoring individuals there is a substantial relationship between their own scores on the measure of extraversion and the number of extraverted traits that they retained in their lists of six traits, in both the mostly-extraverted-character condition, $r(29)=.54, p<$ .01 , and the mostly-introverted-character condition, $r(35)=.49, p<.01$. For high self-monitoring individuals, the relationship between their own scores on the measure of extraversion and the number of extraverted traits that they retained in their list of six traits is a minimal one, in both the mostlyextraverted-character condition, $r(37)=.15$, $n s$, and the mostly-introverted-character condition, $r(32)=.13, n s$.

Moreover, when we entered these correlations into a 2 (high self-monitoring indi-

\footnotetext{
${ }^{5}$ In this analysis, individuals with scores of 15 or more on the Self-Monitoring Scale were classified as high selfmonitoring individuals; those with scores of 10 or less were classified as low self-monitoring individuals. Thus, high self-monitoring individuals represent approximately the upper quartile of the distribution of scores on the Self-Monitoring Scale; low self-monitoring individuals represent the lower quartile of that distribution. The substantially larger number of participants in the second investigation than in the first investigation permitted this classification procedure, which provides a finer differentiation between individuals low and high in self-monitoring than in the first investigation.
} 
viduals vs. low self-monitoring individuals) $\times 2$ (mostly extraverted character vs. mostly introverted character) analysis of variance for correlations (cf. Jones, 1968), that analysis yielded a single main effect for self-monitoring classification. ${ }^{6}$ For low selfmonitoring individuals, the relationship between their own personal levels of extraversion and the degree of extraversion of the character into which they transformed the original character was reliably greater than the corresponding relationship for high selfmonitoring individuals, $F(1, \infty)=5.89, p<$ $.02 .^{7,8}$ Clearly, the evidence of this matrix of correlations supports the hypothesis that low self-monitoring individuals more so than high self-monitoring individuals would transform the characters of the mostly extraverted or mostly introverted situations to which they had been assigned into ones more closely resembling their own personal disposition within the domains of extraversion and introversion.

Did high self-monitoring individuals, more so than low self-monitoring individuals, define the character of the situation they would be more willing to enter in relatively clear and consistent terms? To answer this question, we examined separately the traits retained by those participants whose original characters were discrepant from their own personal dispositions (that is, extraverts assigned to the mostly-introverted-character condition and introverts assigned to the mostly-extraverted-character condition) and the traits retained by those participants whose original characters were congruent with their own personal dispositions (that is, extraverts assigned to the mostly-extraverted-character condition and introverts assigned to the mostly-introverted-character condition). ${ }^{9}$

Consider first those participants who had been assigned to situations whose original characters were discrepant from their own personal dispositions. For these individuals, the same choices that create situations of more clearly defined character (that is, retaining character-defining introverted traits in the mostly-introverted-character condition and character-defining extraverted traits in the mostly-extraverted-character condition) of necessity also create situations of increased discrepancy from their personal dispositions (that is, a situation of more introverted character for extraverts in the mostly-introverted-character condition and a situation of more extraverted character for introverts in the mostly-extraverted-character condition). We already know, based on the analysis of the first matrix of correla${ }^{6}$ In this analysis of variance for correlations, each
correlation is first transformed to a $z$ score (using
Fisher's $r$-to-z transformation) for which the variance
is known (Fisher, 1946, p. 198). Thus, the within-cells
variance in this analysis has infinite degrees of freedom.
7n our sample, high self-monitoring individuals
tended to display a somewhat more restricted range of
scores on the measure of extraversion than did low self-
monitoring individuals. For participants assigned to the
mostly-introverted-character condition, the maximum-
minimum difference in extraversion was the same for
high self-monitoring individuals and for low self-mon-
itoring individuals (16 in each case), but for participants
assigned to the mostly-extraverted-character condition,
the maximum-minimum difference was 13 for high self-
monitoring individuals and 17 for low self-monitoring
individuals. An additional analysis suggests that this
difference does not mean that the lower correlation for
high self-monitoring individuals than for low self-mon-
itoring individuals in the mostly-extraverted-character
condition was an artifact of differences in range of ex-
traversion scores. If we eliminate low self-monitoring
individuals from both ends of the distribution for the
mostly-extraverted-character condition until the maxi-
mum-minimum difference is as small as or smaller than
that for high self-monitoring individuals, we find that
the resulting correlation for low self-monitoring indi-
viduals remains substantial, $r=.45$, $t(27$ ) $=2.62$,
$p<.02$.

${ }^{8}$ We repeated this analysis of variance three times, in each case classifying participants (into upper and lower quartiles) on the basis of their scores on one of the three Briggs et al. (1980) factors instead of their scores on the entire measure of self-monitoring. The main effect that had emerged (with clear statistical significance) from the original analysis employing the entire measure, $F(1, \infty)=5.89, p<.02$, also emerged (with only marginal statistical significance) from the analyses employing each of the factors, Factor 1: $F(1$, $\infty)=2.61, p=.11 ;$ Factor $2: F(1, \infty)=2.61, p=.11 ;$ Factor 3: $F(1, \infty)=3.91, p=.05$. Evidently, for purposes of this analysis, each factor can reproduce to some extent the main effect produced by the entire measure, although no factor seems to perform as well as the entire measure.

${ }^{9}$ In this and the subsequent analysis, individuals with scores of 16 or more on the Extraversion scale of the Eysenck Personality Inventory were classified as extraverts; those with scores of 10 or less were classified as introverts. Thus, extraverts represent approximately the upper quartile of the distribution of scores on this measure; introverts, the lower quartile of this distribution. 
Table 4

Transforming Situations: Increasing the Clarity of the Character of the Situation

\begin{tabular}{|c|c|c|}
\hline \multirow[b]{2}{*}{$\begin{array}{l}\text { Situational } \\
\text { assignment }\end{array}$} & \multicolumn{2}{|c|}{ Situation } \\
\hline & $\begin{array}{c}\text { Mostly } \\
\text { extraverted } \\
\text { character }\end{array}$ & $\begin{array}{c}\text { Mostly } \\
\text { introverted } \\
\text { character }\end{array}$ \\
\hline \multicolumn{3}{|c|}{ Congruent character } \\
\hline$r$ & .13 & -.07 \\
\hline$n$ & 35 & 27 \\
\hline \multicolumn{3}{|c|}{ Discrepant character } \\
\hline$r$ & $.41^{*}$ & $.38^{*}$ \\
\hline$n$ & 31 & 33 \\
\hline
\end{tabular}

Note. Correlations are calculated between participants' scores on self-monitoring and the number of characterdefining traits in their lists of six traits.

$* p<.05$.

tions, that low self-monitoring individuals were particularly likely to create situations whose characters were congruent with their own personal dispositions. That is, from the perspective of the predictions now under scrutiny, we know that low self-monitoring individuals assigned to situations whose original characters were discrepant from their own personal dispositions retained relatively few character-defining traits. If it is also true, as we have predicted, that high selfmonitoring individuals assigned to such situations retained relatively many characterdefining traits, then we would expect that for those individuals assigned to situations whose original characters were discrepant from their own personal dispositions, there would exist substantial correlations between their scores on the Self-Monitoring Scale and the number of character-defining traits that they retained in their list of six traits.

Consider now those participants who had been assigned to situations whose original characters were congruent with their own personal dispositions. For these individuals, the same choices that create a situation of more clearly defined character (that is, retaining character-defining traits in their list of six traits) of necessity also create situations whose characters are of increased congruence with their own personal dispositions (that is, a situation of more extraverted character for extraverts assigned to the mostly- extraverted-character condition and a situation of more introverted character for introverts assigned to the mostly-introverted-character condition). We already know, based on the analysis of the first matrix of correlations, that low self-monitoring individuals were particularly likely to create situations whose characters were congruent with their own personal dispositions. That is, from the perspective of the predictions now under scrutiny, we know that low selfmonitoring individuals assigned to situations whose original characters were congruent with their own personal dispositions retained relatively many character defining traits. If it is also true, as we have predicted, that high self-monitoring individuals assigned to such situations retained relatively many character-defining traits, then we would expect that for those individuals assigned to situations whose original characters were congruent with their own personal dispositions, there would exist minimal correlations between their scores on the Self-Monitoring Scale and the number of character-defining traits that they retained in their list of six traits.

Correlations between participants' scores on the Self-Monitoring Scale and the number of character-defining traits that they retained in their list of six traits are presented in Table 4. Examination of these correlations reveals that, in accord with our predictions, the correlations are substantial for participants assigned to situations whose original characters were discrepant from their own personal dispositions, in both the mostly-extraverted-character condition, $r(29)=.41$, $p<.05$, and the mostly-introverted-character condition, $r(31)=.38, p<.05$. Also in support of our predictions, the correlations are minimal for participants assigned to situations whose original characters were congruent with their own personal dispositions, in both the mostly-extraverted-character condition, $r(33)=.13$, ns, and the mostly-introverted-character condition, $r(25)=-.07, n s .^{10}$

Furthermore, a 2 (congruent character vs.

\footnotetext{
${ }^{10}$ The substantial correlations between low self-monitoring individuals' extraversion score and the number of extraverted traits included in their lists reported in
} 
discrepant character) $\times 2$ (mostly extraverted character vs. mostly introverted character) analysis of variance on this correlation matrix yielded a single reliable main effect. For participants assigned to situations whose original character was discrepant from their personal dispositions, the relationship between their scores on the Self-Monitoring Scale and the number of character-defining traits that they retained in their lists of six traits was reliably greater than was the corresponding relationship for participants assigned to situations whose original character was congruent with their personal dispositions, $F(1, \infty)=4.24, p<.05 .^{11}$

Taken together, the results of these two correlational analyses provide considerable support for our theoretical predictions. Low self-monitoring individuals, more so than high self-monitoring individuals, defined the character of the social situation that they would be more willing to enter as one relatively congruent with their own personal dispositions. High self-monitoring individuals, more so than low self-monitoring individuals, defined the character of the social situation that they would be more willing to enter in relatively clear and consistent terms.

\section{Discussion}

In their responses to the items of the SelfMonitoring Scale (Snyder, 1974), high selfmonitoring individuals claim, among other things, that "In different situations and with different people, I often act like very different persons," an assertion that has been corroborated by empirical documentation of marked situation-to-situation shifts in their self-presentation and social behavior (Sny-

Table 3 practically ensure that these minimal correlations are due to individuals assigned situations of congruent character retaining relatively many character defining traits, as we had predicted. We confirmed this occurrence by calculating the mean $z$ score of the number of character defining traits for those individuals assigned to situations whose characters were congruent with their own personal dispositions. These average $z$ scores were in fact substantial and significantly different. from zero in both the mostly-extraverted-character condition, $M_{z}=.45, t(31)=2.88, p<.01$, and the mostlyintroverted-character condition, $M_{z}=.73, t(26)=3.55$, $p<.01$. der, 1979). By contrast, in their responses to the items of the Self-Monitoring Scale, low self-monitoring individuals claim, among other things, that "My behavior is usually a reflection of my true inner feelings, attitudes, and beliefs," an assertion that also has been corroborated by empirical documentation of substantial covariation between their social behavior and relevant underlying attitudes and dispositions (Snyder, 1979).

Our concern here has been to specify theoretically and to identify empirically some strategic activities by which high self-monitoring individuals and low self-monitoring individuals each may promote and facilitate enactment of their characteristic behavioral orientations. Specifically, we have suggested that these individuals systematically choose to enter and to spend time in those social situations and interpersonal settings that are particularly conducive to enactment of their

1 We also performed this analysis of variance three more times using as dependent measures correlations involving participants' scores on each of the three Briggs et al. (1980) factors instead of their scores on the entire measure of self-monitoring. A reliable main effect emerged from the analysis employing Factor $1, F(1$, $\infty)=6.09, p=.014$. However, it is unlikely that this main effect can account for the main effect that emerged from the original analysis employing the entire measure. The entire measure main effect reflects substantial positive correlations in the two situations of discrepant character and only minimal correlations in the two situations of congruent character. In contrast, the Factor 1 main effect reflects one substantial negative correlation in one of the situations of congruent character and minimal or modest correlations everywhere else. No main effects emerged from the analysis employing either Factor $2, F(1, \infty)=0.00$, ns, or Factor $3, F(1, \infty)=$ 2.30 , ns. Evidently, for purposes of this analysis, no scores or individual factors can stand in for scores on the entire measure of self-monitoring.

When considered together, the three sets of analyses involving the Briggs et al. (1980) factors (reported in Footnotes 3, 8, and 11) suggest that some links do exist between individual factors and the measures of choosing social situations employed in these investigations. Yet, these analyses in no way suggest that the differing bases on which individuals high and low in self-monitoring choose their social situations can be accounted for exclusively by one or other individual factor. Instead, the differential responsiveness of high self-monitoring individuals and low self-monitoring individuals to the clarity of the definition and the congruence with personal dispositions of the character of social situations seems to be more consistently and reliably identified by the entire measure of self-monitoring than by any component portion of that measure. 
characteristic behavioral orientations. From a theoretical perspective, we anticipated that high self-monitoring individuals would systematically choose to enter and to spend time in interpersonal settings that provide clear specifications of the type of character one ought to be, or should appear to be, in those social situations. At the same time, we anticipated that low self-monitoring individuals would systematically choose to enter and to spend time in social situations that call for the behavioral expression of their own personal dispositions. Indeed, both empirical investigations of the willingness to enter and to spend time in social situations provided converging support for these theoretical predictions.

What are the consequences of the strategic choice of social situations as it is differently practiced by high self-monitoring and low self-monitoring individuals? To the extent that high self-monitoring individuals habitually gravitate toward social situations of clearly defined character, they effectively provide themselves with social settings and interpersonal contexts that are well-suited to enacting their characteristic behavioral orientations. They choose social contexts in which they can readily mold and tailor their self-presentational and social behaviors to fit situational and interpersonal specifications of behavioral appropriateness. To the extent that low self-monitoring individuals habitually gravitate toward social situations that call for personalities of the type actually possessed by them, they effectively provide themselves with social settings and interpersonal contexts that are well-suited to enacting their characteristic behavioral orientations. They choose social contexts in which they can readily behave in ways that accurately reflect and meaningfully communicate their own attitudes, feelings, and dispositions. ${ }^{12}$

From this perspective, the strategic choice of social situations may enable both high self-monitoring and low self-monitoring individuals to regularly and consistently enact their characteristic behavioral orientations. Moreover, by their strategic choice of situations, high self-monitoring individuals and low self-monitoring individuals may create for themselves social worlds that ensure the perpetuation of their self-monitoring propensities-social worlds in which high selfmonitoring individuals continue to be high self-monitors and low self-monitoring individuals continue to be low self-monitors.

Over and above the implications of choosing social situations for understanding selfmonitoring processes, these activities may contribute to a more general understanding of behavior in social contexts. Our full understanding of social behavior may depend not only upon considerations of the behaviors that occur in social contexts but also upon considerations of the processes by which individuals find themselves in those social contexts in the first place. After all, individuals cannot respond to social situations without first encountering them. To the extent that the situations that individuals encounter are ones of their own choosing, understanding the processes by which individuals choose their social settings and interpersonal contexts becomes essential to understanding the events that subsequently transpire in those social contexts (for an elaboration of this argument, see Snyder, 1981). According to this point of view, the familiar proposition that an individual's behavior in a social situation is determined by characteristics of both the individual and the situation should be amended to propose that social behavior is a function of the individual, the situation, and the processes by which the individual finds himself or herself in that situation. Only then will it be possible to construct a

\footnotetext{
${ }^{12}$ A further implication of these findings concerns the characterization of low self-monitoring individuals. Although considerable empirical evidence suggests that their behavior in social contexts typically is highly responsive to dispositional influences and only minimally responsive to situational influences, low self-monitoring individuals should not be characterized as totally unconcerned with situational considerations. Indeed, the results of these two investigations of choosing social situations suggest that low self-monitoring individuals are attentive and responsive to situational considerations (in particular, those situational considerations that permit them to assess the extent to which situations provide opportunities to act in accord with their own personal dispositions) prior to entering social situations. That is, low self-monitoring individuals are best characterized as individuals who are responsive to situational characteristics before entering social situations but who, once in social situations, are then responsive to their own dispositional attributes.
} 
social personality psychology that fully captures the interaction between individuals and social situations.

\section{References}

Briggs, S. R., Cheek, J. M., \& Buss, A. H. An analysis of the Self-Monitoring Scale. Journal of Personality and Social Psychology, 1980, 38, 679-686.

Eysenck, H. J., \& Eysenck, S. B. G. Manual for the Eysenck Personality Inventory. San Diego: Educational and Industrial Testing Service, 1968.

Fisher, R. A. Statistical methods for research workers (10th ed.). Edinburgh: Oliver and Boyd, 1946.

Gabrenya, W. K., Jr., \& Arkin, R. M. Factor structure and factor correlates of the Self-Monitoring Scale. Personality and Social Psychology Bulletin, 1980, 6, 13-22.

Jones, M. B. Correlation as a dependent variable. Psychological Bulletin, 1968, 70, 69-72.

Hays, W. L. Statistics for the social sciences (2nd ed.). New York: Holt, Rinehart \& Winston, 1973.

Lippa, R. Expressive control and the leakage of dispositional introversion-extraversion during role-played teaching. Journal of Personality, 1976, 44, 541-559.

Snyder, M. The self-monitoring of expressive behavior. Journal of Personality and Social Psychology, 1974, $30,526-537$.
Snyder, M. Self-monitoring processes. In L. Berkowitz (Ed.), Advances in experimental social psychology (Vol. 12). New York: Academic Press, 1979.

Snyder, M. On the influence of individuals on situations. In N. Cantor \& J. F. Kihlstrom (Eds.), Personality, cognition, and social interaction. Hillsdale, N.J.: Erlbaum, 1981 .

Snyder, M., \& Ickes, W. Personality and social behavior. In G. Lindzey \& E. Aronson (Eds.), Handbook of social psychology (3rd ed.). Reading, Mass.: Addison-Wesley, in press.

Snyder, M., \& Monson, T. C. Persons, situations, and the control of social behavior. Journal of Personality and Social Psychology, 1975, 32, 637-644.

Snyder, M., \& Swann, W. B., Jr. When actions reflect attitudes: The politics of impression management. Journal of Personality and Social Psychology, 1976, 34, 1034-1042.

Snyder, M., \& Tanke, E. D. Behavior and attitude: Some people are more consistent than others. Journal of Personality, 1976, 44, 510-517.

Zanna, M. P., Olson, J. M., \& Fazio, R. H. Attitudebehavior consistency: An individual difference perspective. Journal of Personality and Social Psychology, 1980, 38, 432-440.

Received May 11, 1981 